\title{
Investigation of factors affecting mercury emission from subtropical forest soil: A field controlled study in southwestern China
}

\author{
Jun Zhou ${ }^{\mathrm{a}, \mathrm{b}}$, Zhangwei Wang a,*, Xiaoshan Zhang a, Ting Sun ${ }^{\mathrm{a}, \mathrm{b}}$ \\ ${ }^{a}$ Research Center for Eco-Environmental Sciences, Chinese Academy of Sciences, Beijing 100085, China \\ ${ }^{\mathrm{b}}$ University of Chinese Academy of Sciences, Beijing 100049, China
}

\section{A R T I C L E I N F O}

\section{Article history:}

Received 13 March 2015

Revised 24 June 2015

Accepted 11 October 2015

Available online 21 October 2015

\section{Keywords:}

Mercury flux

Turnover times

Total gaseous mercury

Moisture and watering

Understory

\begin{abstract}
A B S T R A C T
Recent studies demonstrated that subtropical forest in China was considered as a large pool of atmospheric mercury and soils of forested watershed is a large reservoir of atmospherically deposited mercury. However, forest ecosystems not only act as sinks but also as sources of previously deposited mercury emitted back to the atmosphere. In this study a field controlled method was performed in Tieshanping National Forest Park (TNFP) to identify the effects of the most important parameters that controlled mercury emissions from soil surfaces, including chamber flushing flow turnover times (TOTs), soil water content and watering, total gaseous mercury (TGM) in air and understory. Flushing flow rates significantly affected the calculation of mercury flux and the optimal TOTs were $0.94 \mathrm{~min}$ in the forest. TGM in atmosphere was significantly inhibited mercury emission from soils, and the deposited mercury was not absorbed firmly by the soils in a short time and emitted back to atmosphere rapidly when TGM concentration decreased. Higher soil moisture reduced the emission of mercury and initial watering produces a spike in the mercury emissions due to the interstitial soil gas mercury displaced by infiltrating water physically. However, subsequent watering was reducing the fluxes, because surface soil was saturated and soil pores were blocked by water film and inhibited the soil mercury emission. Soils under the understory had a higher mercury concentrations and deep organic layers. However, the fluxes of soil under the understory significantly were inhibited in daytime because solar radiation was blocked by the understory and the higher litter layer.
\end{abstract}

(C) 2015 Elsevier B.V. All rights reserved.

\section{Introduction}

Mercury is a highly toxic heavy metal and is well-known global contaminant that can continuously go through the deposition to terrestrial and aquatic ecosystems and re-emission back to atmosphere by natural sources (Poissant et al., 2000; Chung and Chon, 2014). Natural sources generally include the emissions from natural reservoirs (e.g., volcanic activity and forest fires) and the re-emission of mercury deposited previously from anthropogenic and natural sources (Zhang et al., 2014). Some recent studies and models of its cycle in the environment suggested that mercury emissions and re-emissions from soil and vegetation were estimated up to $5500-8900$ tons, accounting for $19-51 \%$ of the current release to the atmosphere from all sources (UNEP, 2013). Furthermore, studies have also reported that mercury evasion from forest and grassland was an important source of total gaseous mercury (TGM) in the atmosphere in the background area (Zhou et al., 2015; Ericksen et al., 2006; Choi and Holsen, 2009a; Almeida et al., 2009). Therefore, soil/air exchange flux is an important component of the mercury global biogeochemical cycle. Management of this environmental

\footnotetext{
* Corresponding author.

E-mail address: wangzhw@rcees.ac.cn (Z. Wang).
}

contaminant necessitates the accurate measurement of the exchange flux between earth surfaces and the atmosphere (Eckley et al., 2010).

However, unlike the measurement of mercury release from anthropogenic point sources, characterization of emissions from natural sources is difficult, especially from soil, because spatial and temporal variability of mercury emission is controlled by multiple interacting factors, such as experimental methods, substrate mercury content and fractions (Eckley et al., 2010; Liu et al., 2014), soil physical-chemical factors (soil temperature and humidity, soil gas mercury, soil total organic matters (TOM), pH, etc.) (Choi and Holsen, 2009b; Yang et al., 2007) and meteorological parameters (e.g. UV radiation, air temperature, rainfall) (Gabriela et al., 2011; Almeida et al., 2009). However, results of how these factors influence the mercury emissions are often inconsistent and even contradictory (Park et al., 2014). Thus regional field and simulation studies of soil/air flux appear to be particularly important.

Numerous researches have used dynamic flux chambers (DFCs) to measure mercury fluxes from a large assortment of surfaces around the globe (Bash et al., 2007). But it should be noted that short-term variability in $\mathrm{Hg}^{0}$ concentration made contributions to the uncertainty level in DFC-derived flux significantly and relative bias for DFC-derived fluxes was estimated to be $~ 10 \%$, and for $\sim 85 \%$ 
of the measurement (Zhu et al., 2015). Moreover, Lin et al. (2012) demonstrated that flux measured by conventional DFC may be underestimated at low flushing flow rate $\left(\leq 5 \mathrm{~L} \mathrm{~min}^{-1}\right)$ compared to the new DFC, because the direct air flow reduced surface shear in conventional DFC. The difference in chamber volume and flushing flow rate used by researchers has varied by over an order of magnitude and the resulting chamber turnover times (TOTs) have varied by over 2-orders of magnitude, which results in fluxes variation in by order of magnitude (Eckley et al., 2010). However, flushing flow rate or TOTs differ world-widely in measuring fluxes of forest soil, therefore, optimal TOTs are required. In addition, flux between soil and air is the relationship of dynamic diffusion between mercury concentrations of soil gas in soil column underneath the soil surface layer $(0-5 \mathrm{~cm}$, our unpublished data) and TGM in atmosphere, indicating that mercury concentrations variation in atmosphere or soil gas seriously influences the flux (Zhang et al., 2002). Subtropical forest in China is considered as a large pool of atmospheric mercury (Zhou et al., 2013, 2015; Wang et al., 2009), while soils of forested watershed is a large reservoir of atmospherically deposited mercury, accounting for up to $90 \%$ of mercury in forests (Grigal, 2003). Forest ecosystems not only act as sinks but also as sources of previously deposited mercury emitted back to the atmosphere. Previous researches focused mostly on mercury deposition to forest, while the influence factors and process of mercury evasion from forest soil were not studied in detail and the process was not clear. Furthermore, at present, no studies are conducted to explore the influence of TGM in atmosphere and understory on the exchange flux between soil and air. In the current study, a field control experiment is conducted (1) to study the optimal flushing flow rate and TOTs, (2) to isolate the effects of moisture and watering on the emission of mercury from the soil surface, (3) to characterize the influence of TGM in atmosphere and (4) understory (e.g., shrub and fern) on the exchange flux in a subtropical forest in southwestern China.

\section{Materials and methods}

\subsection{Sites description}

This work was conducted at Tieshanping National Forest Park (TNFP) $\left(29^{\circ} 38^{\prime} \mathrm{N}, 104^{\circ} 41^{\prime} \mathrm{E}\right)$, one of the Sino-Norwegian multidisciplinary Integrated Monitoring Program on Acidification of Chinese Terrestrial Systems (IMPACTS) project monitoring sites, is located on a sandstone ridge, $20 \mathrm{~km}$ in the northeast of the metropolitan Chongqing City. The forest stand in TNFP is a Masson Pine dominated, coniferous-broad leave mixed subtropical forest and trees were planted in the 1960s. The soil is typically mountain yellow earth and its texture is haplic acrisol/alisol, which is severely acidified with an acidic pH 3.79 and TOM 12.7\% in the organic horizon (Zhou et al., 2015). Based on our precious study, atmospheric deposition and soil pools of mercury were significantly elevated in TNFP area, which was several or even dozens of times compared to estimates obtained in North America and Europe (Wang et al., 2009; Zhou et al., 2015).

\subsection{Soil properties}

Soil profiles were collected at two locations which were under the understory (ferns) and under the forest canopy without ferns. The two locations were distanced no more than $1 \mathrm{~m}$ and corresponded to the substrates of Experiment 4 in Section 2.4. Soil samples were collected in polyethylene bags and air-dried in a clean environment in our laboratory. Subsequently the air-dried soil samples were homogenized to a size of 150 meshes per inch with a mortar before chemical analysis. For mercury analysis in soil samples, a DMA-80 direct mercury analyzer (Milestone Ltd., Italy) was used. TOM content in forest soils and litter was determined by using the sequential loss on ignition (LOI) (Zhou et al., 2013).

\subsection{Flux measurement}

The soil/air mercury fluxes from forest soil were conducted in the field of TFNP and determined by using a coupling method of DFCs and manual pure gold quartz trap (Fig. 1). A semi-cylindrical quartz glass and open-bottom DFCs ( $4.71 \mathrm{~L}$ ) were used throughout the sampling campaign. The square of the DFCs covering over the soil surface was $20 \times 30 \mathrm{~cm}$ with six inlet holes ( $1 \mathrm{~cm}$ diameter) and a detailed description can be found in Fu et al. (2008). At the outlet of the chamber, an orifice was connected to two exits, one was connected in a regulated suction pump with a flow rate of $5 \mathrm{~L} \mathrm{~min}^{-1}$, whereas the other exit was connected to a gold trap for trapping outlet TGM. On the two opposite sections of the chamber, the other gold trap was placed to trap inlet TGM in the outside air. Sampling flow rate was maintained $0.3-0.4 \mathrm{~L} \mathrm{~min}^{-1}$ by rotameter and the air volume passing through each trap was accurately measured by an integrating volume flow meter. The mercury flux was calculated using the following equation:

$F=\left(C_{0}-C_{i}\right) \times Q / A$

Where $F$ is the mercury flux $\left(\mathrm{ng} \mathrm{m} \mathrm{m}^{-2} \mathrm{~h}^{-1}\right) ; C_{o}$ and $C_{i}$ are the steady state mercury concentration $\left(\mathrm{ng} \mathrm{m}^{-3}\right)$ of the outlet and inlet air stream, respectively; $A$ is the surface area enclosed by the chamber; and $Q$ is the flushing flow rate. All the gold traps which measured inlet and outlet air TGM concentrations in every 20-min interval, were brought back to TNFP Forestry Station for mercury quantification by CVAFS detector (Brooks Rand III, US EPA, Method $1631,1999)$ using dual gold trap amalgamation procedure after every sampling.

For all mercury analysis, quality assurance and quality control measures included all gold traps' recovery, collection efficiency, and the system blanks. All the gold traps' recovery were calibrated by injecting a volume of mercury saturated air with known concentration. The recoveries before and after all experiments were in the range of $97.4-102.9 \%$ and $97.3-103.5 \%$ by using dual gold trap amalgamation procedure and the standard deviation of parallelism was $<2.6 \%$. To detect the collection efficiency of our gold quartz traps before sampling in field, two traps were connected in sequence and collected the ambient lab air for $1 \mathrm{~h}$. For all the traps, there was an extralow concentration beyond the detection limit of the CVAFS on the second traps, which can be ignored. The blanks of the flux sampling system were routinely measured by placing the chamber on a quartz glass surface and the averaged blank was $0.13 \pm 0.21 \mathrm{ng} \mathrm{m}^{-2} \mathrm{~h}^{-1}$ $(\mathrm{n}=10)$. The $\mathrm{r}^{2}$ of the calibration curve had to be greater than 0.99 before the sample analysis could proceed.

Meteorological parameters were collected and averaged over 5-min intervals. Percent moisture was monitored with Time Domain Reflectometry (TDR) Hydra Probe II (SDI-12/RS485) and a Stevenswater cable tester (USA). Air temperature and solar radiation were monitored by TP 101 digital thermometer and GLZ-C photosynthetically radiometer (TOP Ltd., China), respectively.

\subsection{Experimental approach}

Four experiments were performed from September to October in TNFP as follows. For purposes of comparison, mercury fluxes were measured by two chambers side by side simultaneously. The experiments were designed such that the measurement varied one parameter in one chamber, the other one can easily observed the variation of this parameter effect on the mercury flux. Dynamic flux chambers were moved from subsample locations to another one to avoid disturbance from previous experiments. The setup of the dynamic flux chamber for measuring soil/air mercury flux was showed in Fig. 1. 


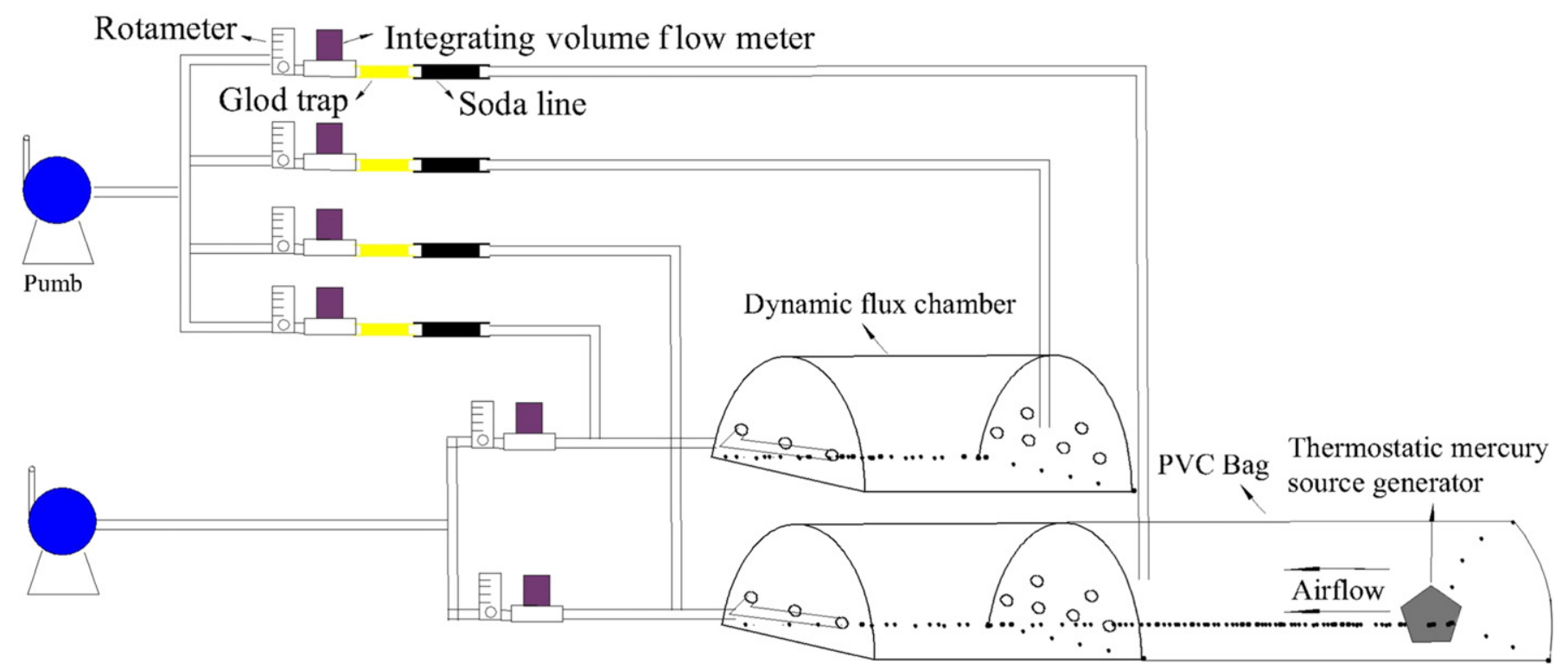

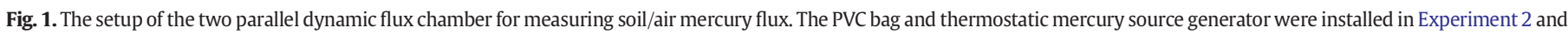
without them in Experiments 1, 3 and 4.

Experiment 1. To determine the influence of flushing flow rate on mercury flux, fluxes were measured at 8 different flow rates (ranging from 1.5 to $20 \mathrm{~L} \mathrm{~min}^{-1}$ ) and TOTs ( 3.1 to $0.24 \mathrm{~min}$ ) in the morning and afternoon for two consecutive days.

Experiment 2. To determine the influence of TGM concentrations in the air (inlet), fluxes were measured through increasing the atmospheric TGM concentrations. The TGM concentrations were increased by a thermostatic mercury source generator, which was able to produce mercury vapor uninterruptedly and was put in to a $50-\mathrm{cm}$ polyvinylchloride bag with open bottoms at both ends. One end was installed and sealed to the bottom of the chamber inlet, and the other end was open to atmosphere. When the pump connected to the chamber was started, smooth airflow with addition of mercury was pumped to the DFCs. Additionally, to measure the inlet TGM concentrations, a Teflon tube was inserted into the PVC bags, close to the inlet of the chamber and connected to a gold trap to measure the TGM concentration exactly. At the outlet of the chamber, another gold trap was placed to absorb outlet TGM.

Experiment 3. The influence of moisture and watering on the soil/air exchange flux was investigated by measuring the flux at a dry soil kept from the precipitation by a plastic film and a wet soil by rainfall event. For watering experiment, throughfall was used and added using a light misting spray bottle to the substrate covered by the flux chamber.

Experiment 4. To determine how effects of understory in forest on the soil/air exchange flux, dynamic flux chambers were placed under the forest canopy with the understory and without understory to measure the fluxes simultaneously.
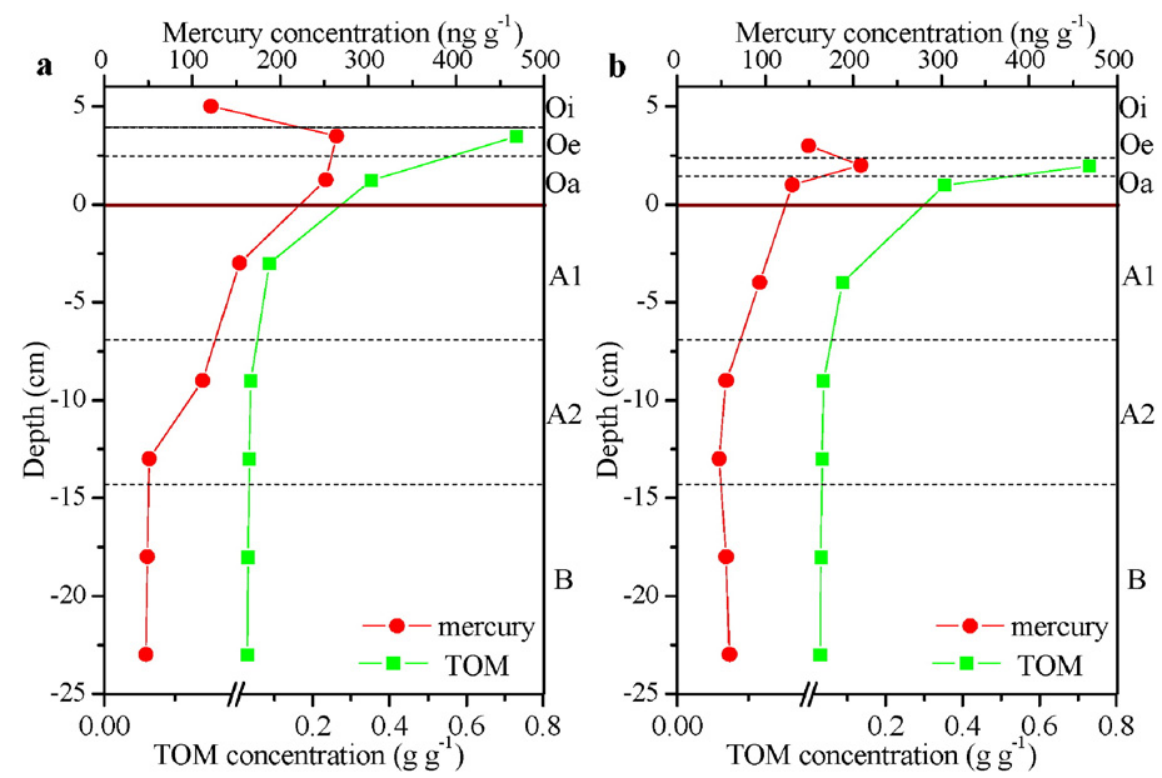

Fig. 2. Mercury distribution in soil profile with understory (a) and without understory (b). 
All measurements of each experiment were performed within the same $9 \mathrm{~m}^{2}$ area to avoid large changes in physical and chemical surface characteristics in the forest.

\section{Results and discussion}

\subsection{Mercury in soils}

Mercury and TOM concentrations in the two soil profiles in the forest of TNFP were shown in Fig. 2, which were under the understory (Dicranopteris linearis) and under the canopy without understory, respectively. The highest mercury concentrations were observed at the topsoil layer (Oe-A1) and mercury concentrations in soil decreased significantly with depth. We observed significant correlations between mercury and TOM concentrations in both soil profiles $\left(r^{2}=0.75\right.$ and 0.87 for under understory and under without understory, respectively, $\mathrm{p}<0.01$ for both) due to TOM and mercury were originated from litterfall deposition. Below the depth of $10 \mathrm{~cm}$, mercury concentrations were similar in two profiles and did not change obviously. However, soils under the understory had much higher mercury and TOM concentrations and thick organic layers, and the detail reason would be discussed in Section 3.5. Mercury concentrations in topsoil in the studied forest were comparable to the data reported from other forest sites in China (Zhou et al., 2013; Wang et al., 2005; Fu et al., 2010), but higher than those measured in North America (St. Louis et al., 2001; Biswas et al., 2008).

\subsection{Influence of flushing flow rate on the calculation of mercury flux: Experiment 1}

Mercury exchange fluxes were measured at $1.5-20 \mathrm{~L} \mathrm{~min}^{-1}$ flushing flow with a difference of 13 times in the subtropical forest (Fig. 3). The $\Delta C$ represents the difference in $C_{o}$ and $C_{i}$ without the obfuscating influence of the flow multiplier. As TOTs ever decrease, $\Delta C$ gradually decreases while the flux increases until leveling off. When TOTs were decreased and $\Delta C$ was stable, mercury fluxes increased proportionally with flow according to Eq. (1). Therefore, only considered on the effect of different flushing flows, the mercury flux increased from 4.5 to $23 \mathrm{ng} \mathrm{m}^{-2} \mathrm{~h}^{-1}$, with a difference of 5.2-flod in the simulation experiment. Only depending on the flushing flow rate, there can be very large differences in calculation of mercury fluxes. Therefore, it is imperative to identify flow rates that provide an exact estimate for a realistic mercury flux.

Earlier studies supposed that the amount of mercury emitted from soil to the chamber at the short TOTs associated with the high flow rates was quickly diluted such that $\Delta C$ approached the value of zero (Eckley et al., 2010; Engle et al., 2006; Lin et al., 2012). But high flushing

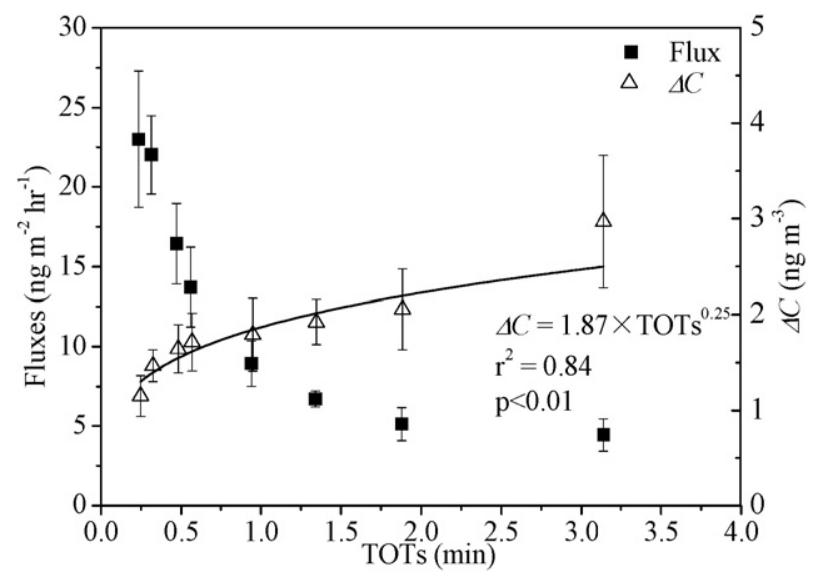

Fig. 3. Measured mercury flux and $\Delta C$ (mean $\pm S D, n=12$ ) at different TOTs in the TNFP. flow rates may alter the chemical/physical conditions within the chamber beyond those expected under normal surface conditions resulting in an enhancement in surface emissions. Instead, slow flushing flow rates may suppress the mercury emission potential due to the excessive buildup of mercury within the chamber. Engle et al. (2006) suggested that while high flow rates and short TOTs are appropriate for measuring flux from soils with high mercury concentrations, lower flow rates and TOTs were more appropriate for low mercury content soils and Eckley et al. (2010) proposed that the optimal flow for measuring mercury flux was at the beginning of the stable $\Delta C$ period, which was chosen as a compromise between competing criteria aimed at creating conditions inside the chamber similar to the outside. The relative stable $\Delta C$ concentrations were about $1.8 \mathrm{ng} \mathrm{m}^{-3}$, and the corresponding flushing flow rate was $5 \mathrm{~L} \mathrm{~min}^{-1}$ and TOT was $0.94 \mathrm{~min}$ in this field study. Therefore, this is the optimal TOTs in subtropical in China. But it should be noted that the $\Delta C$ was still but very gently decreased with the flow rate increased to $10 \mathrm{~L} \mathrm{~min}^{-1}$ in this experiment and the variability in the flux data obtained at a given flow rate is believed to result from variations in environmental conditions during the experiments. While the experiments were performed in the warm season with the temperature range of $24-30^{\circ} \mathrm{C}$ and solar radiation range of $10-95 \mathrm{~W} \mathrm{~m}^{-2}$ under the forest canopy, the flow rate in cold seasons may need more studies to achieve a stable $\Delta C$ optimal flow rate.

\subsection{Influence of atmospheric TGM on the mercury flux: Experiment 2}

This is the first simulation study, to the best of our knowledge, to explore the relationship between TGM concentrations and the soil/air mercury exchange flux. Three groups of added TGM and control treatments were tested in the subtropical forest and the exchange fluxes between soil and air were significantly decreased with the increasing of outlet TGM concentrations (Fig. $4 a-c, p<0.01$ for all), indicating that TGM restrained soil mercury emission and induced strong atmospheric mercury depositions. This result was in agreement with some previous researches which observed net deposition during periods of elevated air concentrations from different substrates in mine areas (Nacht and Gustin, 2004; Wang et al., 2005, 2007a, 2007b; Eckley et al., 2011). Wang et al. (2007a) suggested that mercury exchange flux between soil and air was controlled by two aspects: one was the rate of mercury diffusion on interface between TGM in soil air and the above atmosphere and the other one was the rate of mercury adsorption by soil surface. However, based on the two-resistance exchange interface model, both interfacial exchange characteristics and mercury diffusion potential controlled the mercury exchange flux between soil and air and the exchange flux was calculated from the gradient of TGM concentration between soil air and the above atmosphere as $F=H_{i}\left(C_{s}-C_{a}\right)$, where $H_{i}$ was the overall mercury exchange coefficient of air/soil exchange interface, $F$ was the overall mercury exchange flux, $C_{s}$ and $C_{a}$ were the mercury concentrations of soil air and above atmosphere (Zhang et al., 2002). According to the equation, elevated TGM concentration in above atmosphere will decrease the potential of mercury diffusion from soil to the atmosphere. Thus, this could lead to the rate of mercury diffusion from soil decreasing and even mercury diffusing from the ambient air to soil air (negative flux). Synthetically, highly elevated air mercury concentrations can inhibit/decrease mercury emission flux from soil.

A great number of studies proved that many meteorological parameters can influence mercury exchange flux between soil and air including UV radiation, air temperature, solar radiation and rainfall, etc. (Gabriela et al., 2011; Almeida et al., 2009). In the control group (no addition of TGM), mercury exchange flux showed a significant correlation with air temperature and solar radiation ( $\mathrm{p}<0.01$ for all) (Fig. $4 \mathrm{a}$ and $\mathrm{b}$ ). These meteorological parameters can accelerate the rate of $\mathrm{Hg}^{2+}$ reduction to $\mathrm{Hg}^{0}$ in water under biotic and abiotic effects. Our observations consisted well with the research results of many years (Xiao et al., 1991; Fu et al., 2008; Liu et al., 2014). However, at the specific 

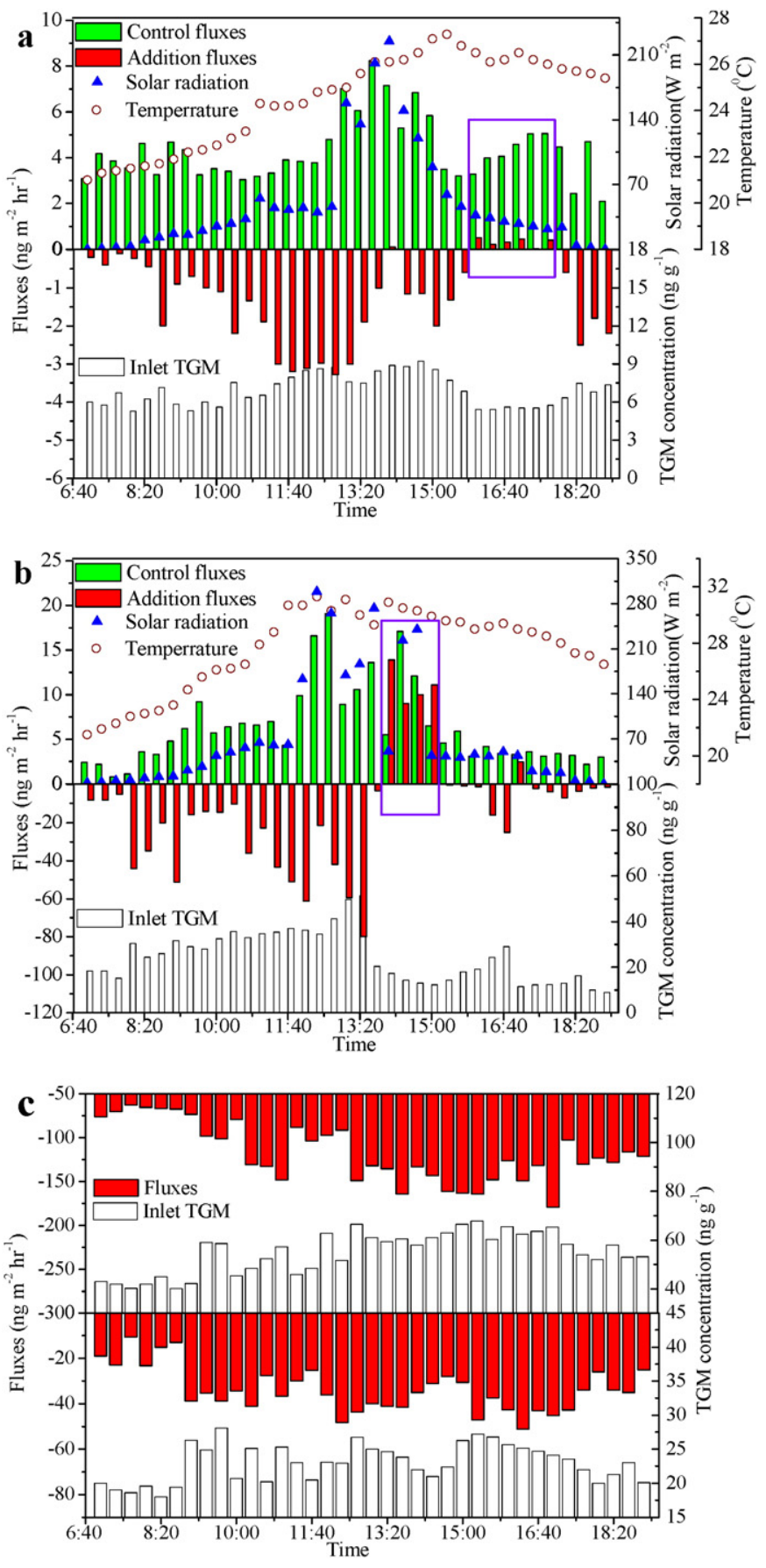

Fig. 4. The soil/air mercury fluxes and meteorological parameters for the addition of outlet TGM concentration.

conditions of added and elevated TGM concentrations above the ground, air TGM concentrations play a dominant role in controlling mercury emission from soil in spite of higher temperature and solar radiation at noon time. Regression analysis based a series of three experiments involving different outlet TGM concentrations, showed a significant negative correlation between the air TGM concentrations and the exchange fluxes (Fig. $5, \mathrm{r}^{2}=0.9008, \mathrm{p}<0.001$ ), although our experiments were not conducted in the same day and with different meteorological conditions.

Mercury emission was observed with measured deposition that was appeared after a significantly deposited during a relative lower air mercury concentrations (Fig. 3a and b). However, similar TGM concentrations at inlet of DFCs were observed at the beginning of experiments,

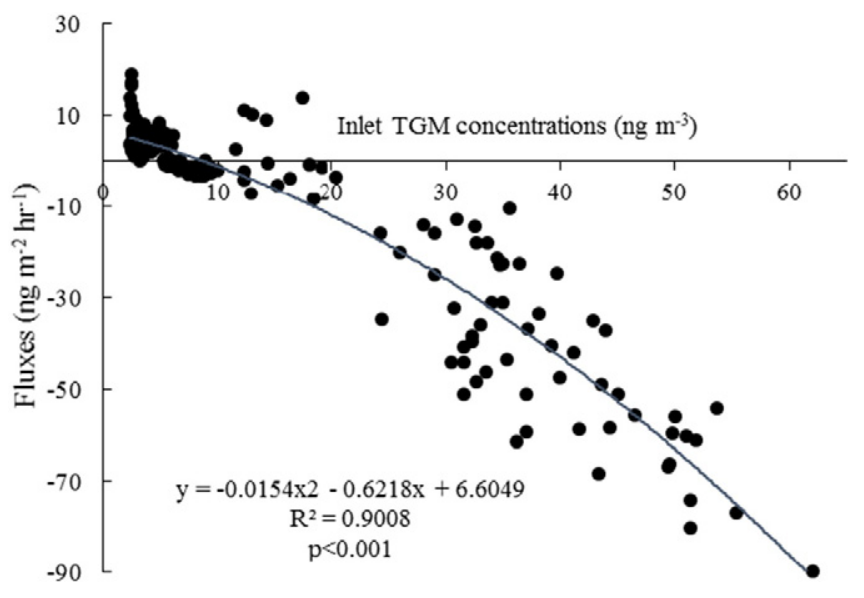

Fig. 5. Correlation between air TGM concentrations and soil/air mercury fluxes.

and the fluxes were the net deposition. For example, while the TGM concentrations were relatively stable and higher (median $8.1 \mathrm{ng} \mathrm{m}^{-3}$, range: 6.5 to $9.2 \mathrm{ng} \mathrm{m}^{-3}$ ) from 11:00 to $16: 00$ in the added lower TGM group, the fluxes were the net deposition and shown in Fig. 4a. Then the TGM concentrations from the outlet of DFCs decreased subsequently to averaged $5.5 \mathrm{ng} \mathrm{m}^{-3}$, and the fluxes were net emission (Fig. 4a). And after that mercury was deposition again with the outlet TGM concentrations increasing. Similar and more striking results were also observed in the addition of higher TGM group (Fig. 4b), and the emission fluxes were comparable between control and addition treatments while the outlet concentrations differed 4-5 times. Meanwhile, the meteorological condition (e.g., temperature and solar radiation) was more beneficially facilitated the soil $\mathrm{Hg}^{0}$ production before the net emission in both experiment groups. Thus, this suggests that a component of the deposited mercury was partly emitted back to the atmosphere.

\subsection{Influence of soil water content and watering on the mercury flux: Experiment 3}

Fig. 6 showed the mercury fluxes under two different soil water contents and the result showed that the mercury emission was higher with the low soil moisture $\left(14.0 \pm 8.2 \mathrm{ng} \mathrm{m}^{-2} \mathrm{~h}^{-1}\right)$ than that with high moisture content $\left(10.5 \pm 6.2 \mathrm{ng} \mathrm{m}^{-2} \mathrm{~h}^{-1}\right)$ but not significant $(\mathrm{p}>$ $0.05)$. However, this was not consistent with previous findings which suggested that more soil water solution could dissolve more mercury from soil solid phase, facilitating its release from both phases (Gustin, 2003; Kocman and Horvat, 2010) and Zarate-Valdez et al. (2006) has also suggested that soil water increasing often resulted in a decrease of soil redox potential, enhancing the conversion of $\mathrm{Hg}^{2+}$ to $\mathrm{Hg}^{0}$. Due

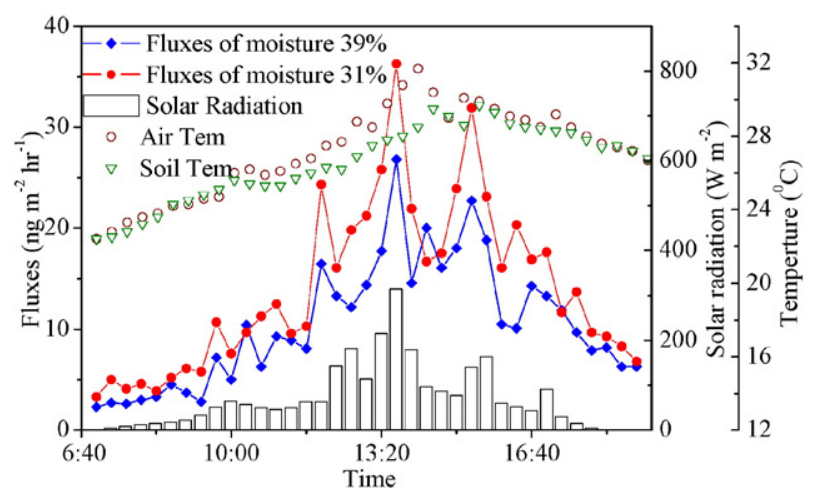

Fig. 6. The soil/air mercury fluxes and meteorological parameters for different soil water contents. 
to the limitations of field conditions, lower soil moisture than 30\% was not studied in this experiment, but Wang et al. (2014) have studied the mercury fluxes of the undisturbed soil sample in the laboratory with the moisture from 2 to $20 \%$, which were collected from the same area as our experiment performed. They found that increase of soil moisture content will usually enhanced the amount of mercury release. If we combined these two experiments together, we may find that the fluxes were firstly increased with soil moisture increasing and then decreased with it. But it should be noted that these experiments were not conducted in the same external conditions and the synergistic influence with humidity on the flux may not remain the same (Park et al., 2014). These would be similar to the study of Gustin and Stamenkovic (2005) and Xin et al. (2007) which observed that the fluxes were enhanced gradually with the substrate moisture decreasing, and then the fluxes were decreased with the soil moisture continuous decreasing. Gustin and Stamenkovic (2005) and Briggs and Gustin (2013) supposed the possible reason that soil with high water volumes, the water will saturate the soil pores and inhibits the soil gas exchange with the atmosphere, inhibiting the mercury emissions from the saturated substrate, whereas we have not tested the soil saturation in the subtropical forest. Briggs and Gustin (2013) also suggested that soil moisture was the most important parameter predicting mercury flux and the evaporative stage of soil moisture was used to partition the parameters that are most important for controlling mercury flux as the soils dried.

The time series for the two adding water events are given in Fig. 7a and b, respectively. Fig. 7a gives the soils moisture at the same level at the beginning, then two addition of water events $(150 \mathrm{~mL})$ was occurred in one group. Fig. 7b shows the soils with two different moistures (31\% and 39\%) that were added with water $(200 \mathrm{~mL})$ twice simultaneously. The time of the adding water event is denoted by the vertical arrow on the abscissa (labeled as "WA"). Two adding water campaigns were conducted in the two experiments, which was at 8:20 with lower temperature and solar radiation, and 13:00 with higher temperature and solar radiation.

Compared to the control experiment (not watering), the fluxes showed a significant and dramatic increase in magnitude immediately on the commencement of the first addition of water event $(8: 20 \mathrm{am})$ in both experiments ( $\mathrm{p}<0.01$ for both), although the temperature and solar radiation was relatively lower in this period and the fluxes of the control group were relatively stable (Fig. 7a and b). Previous studies (Zhang et al., 2002; Nacht and Gustin, 2004; Gustin and Stamenkovic, 2005) observed that addition of water to relative dry soils in amounts less than the needed to saturate the soil surface has been shown to cause an immediate enhancement of mercury emissions. The reason may be that the soil gas which contained higher mercury concentrations (Moore and Castro, 2012), was displaced by infiltrating water physically. In addition, particulate-bound mercury in solid phase was dissolved to aqueous phase, then the reduction by biotic and abiotic actions enhanced the conversion of $\mathrm{Hg}^{2+}$ to $\mathrm{Hg}^{0}$ as we discussed above. Obrist et al. (2014) showed that heavy rainfall led an increment in pore $\mathrm{Hg}^{0}$ concentrations in two forests of California, USA, and they attributed this to the decrease of soil redox potential which enhanced the conversion of $\mathrm{Hg}^{2}+$ to $\mathrm{Hg}^{0}$ and favorable oxidation leading to $\mathrm{Hg}^{\mathrm{O}}$ immobilization under unsaturated soil moisture levels. Although Moore and Castro (2012) did not observed soil moisture correlated with soil TGM concentrations in their field study, they showed the negative correlation between pore $\mathrm{Hg}^{0}$ levels and soil redox potential in forest soils. Therefore, water may enhance mercury release from within the soil profile depending on the depth of penetration, whereas meteorological factor will have the greatest impact at the immediate surface (upper $2 \mathrm{~mm}$ ) as suggested by Xin et al. (2007) and Herbert and Miller (1990).

However, in the second addition of water event (13:20 pm), the fluxes were significantly decreased compared to the first addition of water as well as control group ( $<<0.05)$, while in this period, solar radiation was relative higher. These indicate that water has a more significant influence on mercury fluxes than solar radiation under certain conditions. The second addition of water event of these experiments also showed that depending on soil water holding capacity, a subsequent suppression of flux could occur if sufficient water was added. This may be due to the fact that surface soil was saturated and pores were blocked by water film, therefore inhibited the soil mercury emission (Gustin and Stamenkovic, 2005; Wang et al., 2014). Unlike the without addition of water group, the fluxes of the addition of water groups were not corresponding to air and soil temperature as well as solar radiation. And after the second addition of water, the fluxes were kept relatively stable, especially for the initial soil moisture of $30 \%$. Park et al. (2014) found that temperature enhanced much higher mercury emission from wet soil than dry soil. On the contrary, the effect of UV-B on the mercury emission flux was statistically larger for dry soil than for wet soil, and they also suggested that when water is volatilized from the soil surface, the associated mercury in soil water may also be volatilized as well as enhanced soil mercury emission and the water content in soil suppressed the reduction of $\mathrm{Hg}^{2+}$ by UV-B exposure. This may explained our observations that after the second addition of water, the relative stable soil temperature in the afternoon and lower relative solar radiation under the canopy may resulted in stable volatilization of both water and mercury from soil, while solar radiation has no obviously effect on the fluxes (Fig. 6a and b).

\subsection{Influence of understory on the mercury flux: Experiment 4}

Understory was an important component of forest ecosystems, while species diversity and biomass are controlling factors of soil biota, soil nutrients (Xiong et al., 2008), evapotranspiration, net primary production, net ecosystem $\mathrm{CO}_{2}$ exchange (Dubbert et al., 2014), etc. However, the possible impact of herbaceous vegetation to mercury dynamics in forest ecosystems has been overlooked. Furthermore, because of the large surface area of forest covered by understory, biomass mercury deposition fluxes represent a large portion of mercury dry
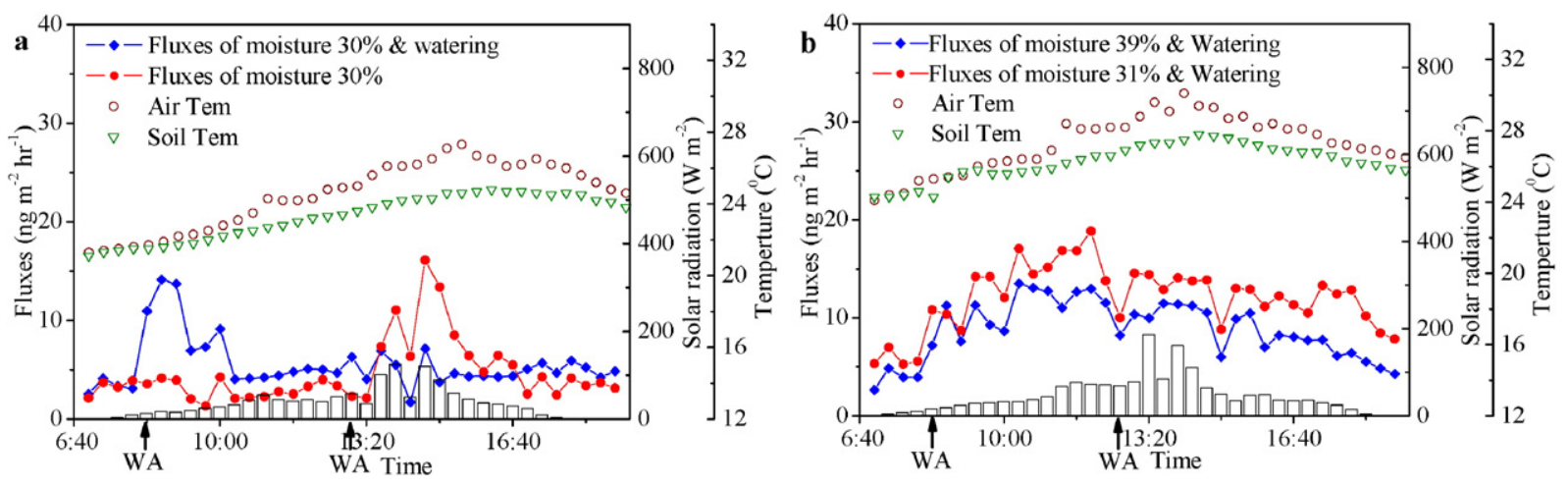

Fig. 7. The soil/air mercury fluxes and meteorological parameters for the addition of water event with the same (a) and different (b) soil water content. 

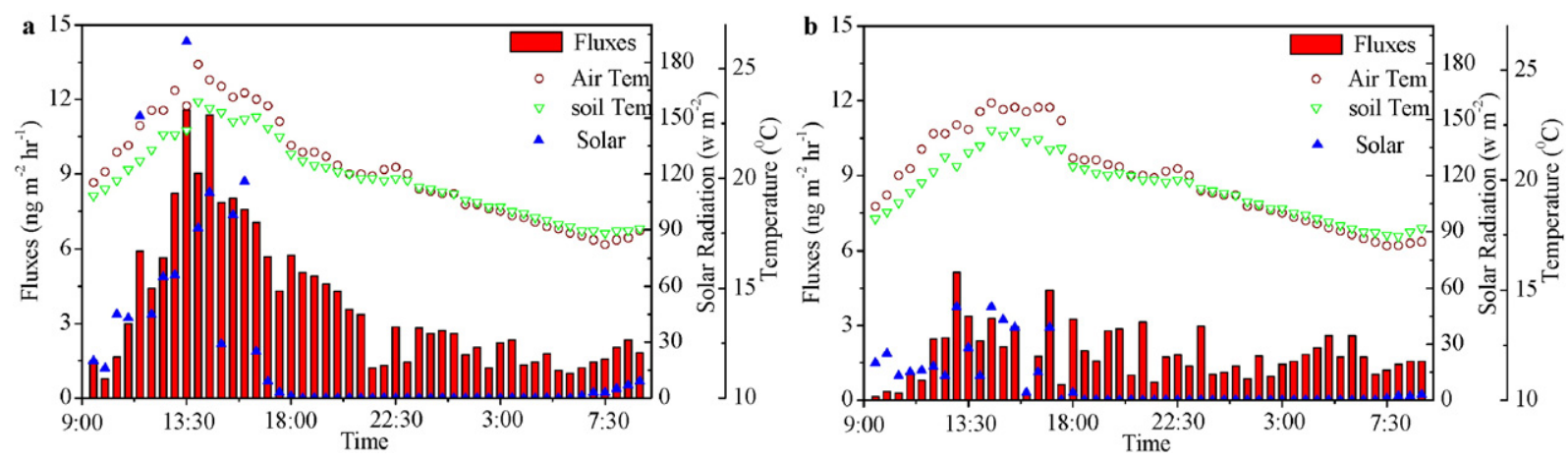

Fig. 8. The soil/air exchange mercury fluxes and meteorological parameters for the soil with understory (a) and without understory (b).

deposition to forested landscapes of terrestrial ecosystems. On the other hand, the forest land covered by understory influenced soil temperature, moisture, and solar radiation (Li et al., 2010), therefore, we hypothesized that in subtropical forest ecosystems the understory layer played an important role on mercury flux between soil and air. In the following, this shall be discussed.

Soils under the canopy with and without understory were tested in $24 \mathrm{~h}$ simultaneously, which were distanced about $1 \mathrm{~m}$, and at night, the fluxes with understory were comparable to that of without understory. But mercury emissions from forest soils without understory were consistently higher than from soils covered by understory in the daytime, which were 5.41 and $2.04 \mathrm{ng} \mathrm{m}^{-2} \mathrm{~h}^{-1}$ (Fig. 8), indicating that understory significantly inhibited mercury emissions $(p<0.001)$. From both of the experiments, mercury emission fluxes were highly correlated to air and soil temperature as well as solar radiation. The difference of mercury fluxes between the two soils was mainly comes from the understory that blocked the sunlight, which can accelerate the photo-reductions of $\mathrm{Hg}^{2+}$ in soils and drove an increase of mercury emissions from soil, and which can also cause an increase in soil temperature, leading to expansion of gases in the soil and emission to the atmosphere (Gabriela et al., 2011; Almeida et al., 2009). Additionally, thicker litter on the soil surface with understory may also block the solar radiation and inhibited mercury emissions.

A similar influence of other greenhouse gas emission flux has been reported to occur within difference, removal and replacement of understory due to changing soil moisture, temperature, etc. Dubbert et al. (2014) observed the understory vegetation contributed importantly to total ecosystem evapotranspiration of carbon with a maximum of $43 \%$. Li et al. (2010) reported that $\mathrm{N}_{2} \mathrm{O}$ fluxes were higher under understory removal as compared to the control without any disturbances, indicating that understory inhabited $\mathrm{N}_{2} \mathrm{O}$ emission in forest. A similar response of soil/air mercury exchange to understory was observed for subtropical forest soils in Fig. 8.

\section{Conclusion}

In this study, the factors of major parameters including sampling flushing flow, air TGM concentrations, soil water content and watering and understory on mercury fluxes were investigated by field controlled studies in a subtropical forest, southwestern China. Flushing flow rates significantly affected the calculation of mercury flux and the optimal TOT is $0.94 \mathrm{~min}$ and the corresponding relative stable $\Delta C$ concentrations were about $1.8 \mathrm{ng} \mathrm{m}^{-3}$ in the subtropical forest southwestern China. Higher TGM concentration in atmosphere significantly suppressed the mercury emission from soils, and the earlier deposited mercury was not absorbed firmly by the soils in a short period and emitted back to atmosphere rapidly, when TGM concentration decreased slightly. Higher soil moisture reduced the emission of mercury from soils and initial watering produces a spike in the emissions of mercury from forest soils due to the interstitial soil air containing $\mathrm{Hg}^{0}$ displaced by infiltrating water physically. However, subsequently watering was reducing emissions, possibly because surface soil was saturated and pores were blocked by water film and inhibited the soil mercury emission. Understory significantly inhibited mercury emissions from forest soils in daytime because of higher litter layer and the sunlight blocked, although soil profiles under the understory have a higher mercury concentrations and larger mercury pools.

\section{Acknowledgements}

This research was funded by the National Basic Research Program of China (No. 2013CB430002), "Strategic Priority Research Program" of the Chinese Academy of Sciences, Grant No. XDB14020205 and the Natural Science Foundation of China (No. 41373124 and 41371461). The anonymous reviewers are acknowledged for providing insightful comments and suggestions.

\section{References}

Almeida, M.D., Marins, R.V., Paraquetti, H.H., Bastos, W.R., Lacerda, L.D., 2009. Mercury degassing from forested and open field soils in Rondonia, Western Amazon, Brazil. Chemosphere 77, 60-66.

Bash, J.O., Bresnahan, P.A., Miller, D.R., 2007. Dynamic surface interface exchanges of mercury: a review and compartmentalized modeling framework. J. Appl. Meteorol. Climatol. 46, 1606-1618.

Biswas, A., Blum, J.D., Keeler, G.J., 2008. Mercury storage in surface soil in a central Washington forest and estimated release during the 2001 Rex Creek fire. Sci. Total Environ. 404, 129-138.

Briggs, C., Gustin, M.S., 2013. Building upon the conceptual model for soil mercury flux: evidence of a link between moisture evaporation and $\mathrm{Hg}$ evasion. Water Air Soil Pollut. 224, 1744.

Choi, H.D., Holsen, T.M., 2009a. Gaseous mercury fluxes from the forest floor of the Adirondacks. Environ. Pollut. 157, 592-600.

Choi, H.D., Holsen, T.M., 2009b. Gaseous mercury emissions from unsterilized and sterilized soils: the effect of temperature and UV radiation. Environ. Pollut. 157, 1673-1678.

Chung, S., Chon, H.T., 2014. Assessment of the level of mercury contamination from some anthropogenic sources in Ulaanbaatar, Mongolia. J. Geochem. Explor. 147, 237-244.

Dubbert, M., Piayda, A., Cuntz, M., Correia, A.C., Silva, F.C., Pereira, J.S., Werner, C., 2014 Stable oxygen isotope and flux partitioning demonstrates understory of an oak savanna contributes up to half of ecosystem carbon and water exchange. Front. Plant Sci. 5, 530.

Eckley, C.S., Gustin, M., Lin, C.-J., Li, X., Miller, M.B., 2010. The influence of dynamic chamber design and operating parameters on calculated surface-to-air mercury fluxes. Atmos. Environ. 44, 194-203.

Eckley, C.S., Gustin, M., Marsik, F., Mille, M.B., 2011. Measurement of surface mercury fluxes at active industrial gold mines in Nevada (USA). Sci. Total Environ. 409, 514-522.

Engle, M.A., Gustin, M.S., Goff, F., Counce, D.A., Janik, C.J., Bergfeld, D., Rytuba, J.J., 2006. Atmospheric mercury emissions from substrates and fumaroles associated with three hydrothermal systems in the western United States. J. Geophys. Res.-Atmos. 111, D17304.

Ericksen, J.A., Gustin, M.A., Xin, M., Weisberg, P.J., Fernandez, G.C.J., 2006. Air-soil exchange of mercury from background soils in the United States. Sci. Total Environ. $366,851-863$.

Fu, X.W., Feng, X., Zhu, W., Rothenberg, S., Yao, H., Zhang, H., 2010. Elevated atmospheric deposition and dynamics of mercury in a remote upland forest of southwestern China. Environ. Pollut. 158, 2324-2333. 
Fu, X.W., Feng, X.B., Wang, S.F., 2008. Exchange fluxes of Hg between surfaces and atmosphere in the eastern flank of Mount Gongga, Sichuan province, southwestern China. J. Geophys. Res. 113, D20306. http://dx.doi.org/10.1029/2008JD009814.

Gabriela, M.C., Williamson, D.G., Brooks, S., 2011. Potential impact of rainfall on the airsurface exchange of total gaseous mercury from two common urban ground surfaces. Atmos. Environ. 45, 1766-1774.

Grigal, D.F., 2003. Mercury sequestration in forests and peatlands: a review. J. Environ. Qual. 32, 393-405.

Gustin, M.S., 2003. Are mercury emissions from geologic sources significant? A status report. Sci. Total Environ. 304, 153-167.

Gustin, M.S., Stamenkovic, J., 2005. Effect of watering and soil moisture on mercury emissions from soils. Biogeochemistry 76, 215-232.

Herbert, V.R., Miller, G.C., 1990. Depth dependence of direct and indirect photolysis on soil surfaces. J. Agric. Food Chem. 38, 913-918.

Kocman, D., Horvat, M., 2010. A laboratory based experimental study of mercury emission from contaminated soils in the River Idrijca catchment. Atmos. Chem. Phys. 10, $1417-1426$.

Li, H., Fu, S., Zhao, H., Xia, H., 2010. Effects of understory removal and N-fixing species seeding on soil $\mathrm{N}_{2} \mathrm{O}$ fluxes in four forest plantations in southern China. Soil Sci. Plant Nutr. 56, 541-551

Lin, C.-J., Zhu, W., Li, X., Feng, X., Sommar, J., Shang, L., 2012. Novel dynamic flux chamber for measuring air-surface exchange of $\mathrm{Hg}^{0}$ from soils. Environ. Sci. Technol. 46, 8910-8920.

Liu, F., Cheng, H., Yang, K., Zhao, C., Liu, Y., Peng, M., Li, K., 2014. Characteristics and influencing factors of mercury exchange flux between soil and air in Guangzhou City. J. Geochem. Explor. 139, 115-121.

Moore, C.W., Castro, M.S., 2012. Investigation of factors affecting gaseous mercury concentrations in soils. Sci. Total Environ. 419, 136-143.

Nacht, D.M., Gustin, M.S., 2004. Mercury emissions from background and altered geologic units throughout Nevada. Water Air Soil Pollut. 151, 179-193.

Obrist, D., Pokharel, A.K., Moore, C., 2014. Vertical profile measurements of soil air suggest immobilization of gaseous elemental mercury in mineral soil. Environ. Sci. Technol. 48, 2242-2252.

Park, S.Y., Holsen, T.M., Kim, P.R., Han, Y.J., 2014. Laboratory investigation of factors affecting mercury emissions from soils. Environ. Earth Sci. 72, 2711-2721.

Poissant, L., Amyot, M., Pilote, M., Lean, D., 2000. Mercury water-air exchange over the upper St. Lawrence river and Lake Ontario. Environ. Sci. Technol. 34, 3069-3078.

St. Louis, V.L., Rudd, J.W.M., Kelly, C.A., Hall, B.D., Rolfhus, K.R., Scott, K.J., Lindberg, S.E. Dong, W., 2001. Importance of the forest canopy to fluxes of methyl mercury and total mercury to boreal ecosystems. Environ. Sci. Technol. 35, 3089-3098.

UNEP, 2013. Global Mercury Assessment 2013: Source, Emissions, Releases and Environmental Transport.

US EPA, Method 1631, 1999. Revision B: Mercury in Water by Oxidation, Purge and Trap, and Cold Vapor Atomic Fluorescence Spectrometry. United States Environmental Protection Agency, pp. 1-33.
Wang, Q., Luo, Y., Du, B., Ye, Z., Duan, L., 2014. Influence factors of mercury emission flux from forest soil at Tieshangping, Chongqing. Environ. Sci. 5 (35), 1922-1927 (In Chinese with English abstract).

Wang, S., Feng, X., Qiu, G., Shang, L., Li, P., Wei, Z., 2007a. Mercury concentrations and air/ soil fluxes in Wuchuan mercury mining district, Guizhou province, China. Atmos. Environ. 41, 5984-5993.

Wang, S.F., Feng, X.B., Qiu, G.L., Fu, X.W., Wei, Z.Q., 2007b. Characteristics of mercury exchange flux between soil and air in the heavily air-polluted area, eastern Guizhou, China. Atmos. Environ. 41, 5584-5594.

Wang, S.F., Feng, X.B., Qiu, G.L., Wei, Z.Q., Xiao, T.F., 2005. Mercury emission to atmosphere from Lanmuchang $\mathrm{Hg}$-Ti mining area, Southwestern Guizhou, China. Atmos. Environ. 39, 7459-7473.

Wang, Z.W., Zhang, X.S., Xiao, J.S., Ci, Z.J., Yu, P.Z., 2009. Mercury fluxes and pools in three subtropical forested catchments, southwest China. Environ. Pollut. 157, 801-808.

Xiao, Z.F., Munthe, J., Schroeder, W.H., Lindqvist, O., 1991. Vertical fluxes of volatile mercury over forest soil and lake surfaces in Sweden. Tellus 43B, 267-279.

Xin, M., Gustin, M., Johnson, D., 2007. Laboratory investigation of the potential for reemission of atmospherically derived $\mathrm{Hg}$ from soils. Environ. Sci. Technol. 41, 4946-4951.

Xiong, Y.M., Xia, H.P., Li, Z.A., Cai, X.A., Fu, S.L., 2008. Impacts of understory and litter removal on soil properties in a subtropical Acacia mangium plantation in China. Plant Soil 304, 179-188.

Yang, Y., Zhang, C., Shi, X., Lin, T., Wang, D., 2007. Effect of organic matter and pH on mercury release from soils. J. Environ. Sci. 19, 1349-1354.

Zarate-Valdez, J.L., Zasoski, R.J., Lauchli, A., 2006. Short-term effects of moisture content on soil solution $\mathrm{pH}$ and soil Eh. Soil Sci. 171, 423-431.

Zhang, H., Lindberg, S.E., Barnett, M.O., Vette, A.F., Gustin, M.S., 2002. Dynamic flux chamber measurement of gaseous mercury emission fluxes over soils. Part 1: simulation of gaseous mercury emissions from soils using a two-resistance exchange interface model. Atmos. Environ. 36, 835-846.

Zhang, H.H., Chen, J.J., Zhu, L., Yang, G.Y., Li, D.Q., 2014. Anthropogenic mercury enrichment factors and contributions in soils of Guangdong Province, South China. J. Geochem. Explor. 144, 312-319.

Zhou, J., Feng, X., Liu, H., Zhang, H., Fu, X., Bao, Z., Wang, X., Zhang, Y., 2013. Examination of total mercury inputs by precipitation and litterfall in a remote upland forest of Southwestern China. Atmos. Environ. 81, 364-372.

Zhou, J., Wang, Z., Zhang, X., Chen, J., 2015. Distribution and elevated soil pools of mercury in an acidic subtropical forest of southwestern China. Environ. Pollut. 202, 187-195.

Zhu, W., Sommar, J., Lin, C.J., Feng, X., 2015. Air-surface exchange of Hg0 measured by collocated micrometeorological and enclosure methods - part 1: data comparability and method characteristics. Atmos. Chem. Phys. 15, 685-702. 